\title{
Which method of left atrium size quantification is the most accurate to recognize thromboembolic risk in patients with non-valvular atrial fibrillation?
}

\author{
Ana Faustino ${ }^{1 *}$, Rui Providência ${ }^{1,2}$, Sérgio Barra ${ }^{1}$, Luís Paiva ${ }^{1}$, Joana Trigo ${ }^{1}$, Ana Botelho ${ }^{1}$, Marco Costa ${ }^{1}$ \\ and Lino Gonçalves ${ }^{1,2}$
}

\begin{abstract}
Background: Left atrial (LA) size is a predictor of cardiovascular outcomes in patients in sinus rhythm, whereas conflicting results have been found in atrial fibrillation (AF). This study aims to: (1) Evaluate the accuracy of LA size to identify surrogate markers of an increased thromboembolic risk in patients with AF; (2) Assess the best method to evaluate LA size in this setting.
\end{abstract}

Methods: Cross-sectional study enrolling 500 consecutive patients undergoing transthoracic and transesophageal echocardiography evaluation during a non-valvular AF episode. LA size was measured on transthoracic echocardiography using several methods: anteroposterior diameter, area in four-chamber view, and volumes by the ellipsoid, single- and biplane area-length formulas. Surrogate markers of stroke were evaluated by transesophageal echocardiography: LA appendage (LAA) thrombus, LAA low flow velocities, dense spontaneous echocardiographic contrast and LA abnormality.

Results: Except for non-indexed anteroposterior diameter, increased LA size quantified by all the other methods showed a moderate to high discriminatory power to identify all the surrogate markers of stroke. A higher accuracy was observed for indexed LA area in four-chamber view (LAA thrombus: $A U C=0.708, \mathrm{Cl}_{95 \%}$ 0.644- 0.772, $\mathrm{p}<0.001$; LAA low flow velocities: $A \cup C=0.733, C_{95 \%}$ 0.674- 0.793, $p<0.001$; dense spontaneous echocardiographic contrast: $A U C=0.693, C_{95 \%}$ 0.638- 0.748, $\mathrm{p}<0.001 ; \mathrm{LA}$ abnormality: $\mathrm{AUC}=0.705, \mathrm{Cl}_{95 \%}$ 0.654-0.755, $\left.\mathrm{p}<0.001\right)$, indexed single-plane area-length volume (LAA thrombus: $A U C=0.701, C_{95 \%}$ 0.633-0.770, $p<0.001$; LAA low flow velocities: $A U C=0.726, C l_{95 \%}$ 0.660-0.792, $p<0.001$; dense spontaneous echocardiographic contrast: $A U C=0.673, C_{95 \%} 0.611-0.736, p<0.001$; LA abnormality: AUC = 0.687, $\mathrm{Cl}_{95 \%}$ 0.629-0.744, $\mathrm{p}<0.001$ ), and indexed biplane area-length volume (LAA thrombus: $\mathrm{AUC}=0.707, \mathrm{Cl}_{95 \%} 0.626-0.788$, $p<0.001$; LAA low flow velocities: $A U C=0.737, C l_{95 \%} 0.664-0.810, p<0.001$; dense spontaneous echocardiographic contrast: $\mathrm{AUC}=0.651, \mathrm{Cl}_{95 \%}$ 0.578-0.724, p<0.001; LA abnormality: $\mathrm{AUC}=0.683, \mathrm{Cl} 95 \%$ 0.617-0.749, $\mathrm{p}<0.001$ ), without significant difference between them. Indexed LA area in four-chamber view and indexed area-length volumes also were independent predictors of surrogate markers of stroke.

Conclusions: Left atrium enlargement is associated with an increased prevalence of surrogate markers of stroke in patients with non-valvular AF. Indexed LA area in four-chamber view and indexed area-length volumes displayed the strongest association.

\footnotetext{
* Correspondence: anacatarina.faustino@gmail.com

${ }^{1}$ Cardiology Department, Coimbra's Hospital and University Centre - General

Hospital, Coimbra, Portugal

Full list of author information is available at the end of the article
} 


\section{Introduction}

Left atrium (LA) dilation has been associated with adverse cardiovascular outcomes in patients with sinus rhythm [1-5]. Among patients with atrial fibrillation (AF), LA enlargement has been suggested as predictor of stroke in some studies [6-11], while others have shown conflicting results [12].

Most investigations regarding the prognostic impact of LA size relied on the antero-posterior diameter measured by M-mode (LA AP diameter). However, this method is based in several geometric assumptions that often result in LA size underestimation [11-16]. Thus, LA areas and volumes derived from two-dimensional transthoracic echocardiography (TTE) seem to provide a more accurate assessment of LA size [17-19].

Transesophageal echocardiography (TEE) allows the assessment of parameters associated with stroke, thromboembolism and adverse prognosis, notably the presence of thrombus in the LA appendage (LAA thrombus) [20], spontaneous echocardiographic contrast (SEC) [20,21], low LA appendage flow velocities (low LAA velocities) [22-25]. The best method to assess the relationship between LA size and the aforementioned LA abnormalities on TEE has never been evaluated.

This study aims to evaluate the accuracy of LA size to identify surrogate TEE markers of an increased risk of stroke (LAA thrombus, low LAA velocities and dense SEC), and also to assess the best method to evaluate LA size in this setting.

\section{Methods}

\section{Study design}

Cross-sectional study enrolling patients undergoing TTE and TEE during a non-valvular AF episode. LA size was measured on TTE by several methods (LA AP diameter, LA area and LA volumes). Surrogate markers of stroke were evaluated by TEE: LAA thrombus, low LAA velocities, dense SEC, and LA ABN. ROC curve analysis was performed to assess the accuracy of the different LA measurements to identify surrogate markers of stroke. All patients provided informed consent for echocardiographic evaluation. The study protocol was approved by Comissão de Ética da Faculdade de Medicina da Universidade de Coimbra (Ref 5/2013).

\section{Patients and eligibility criteria}

Five hundred consecutive adult patients undergoing TTE and TEE during symptomatic episode of nonvalvular AF were enrolled during a 36-month period. AF was identified by an electrocardiogram or endocardial electrograms (in patients with pacemakers or implantable cardioverter defibrillators). Exclusion criteria were moderate or severe mitral stenosis, severe mitral regurgitation, severe aortic stenosis prosthetic mitral or aortic valves, patients with unsuitable images for accurate assessment of TTE measurements or TEE surrogate markers of stroke, or any contraindication to TEE. Most patients had an echocardiogram performed as part of evaluation before electrical cardioversion $(n=466,93.2 \%)$; in the remaining patients, it was conducted for mitral valve disease assessment $(n=14 ; 2.8 \%)$ and stroke evaluation $(n=20 ; 4 \%)$.

\section{Initial data collection}

Demographic, anthropometric, clinical, laboratory, additional echocardiographic and medication data were retrieved from clinical records (outpatient clinic evaluations, emergency department, and hospital-ward admissions). Discharge primary and secondary diagnoses were recorded according to the ICD-10 (international classification of diseases, 10th revision). Duration of AF episode was estimated according to the patients' complaints, previously available clinical records and ECG. In patients with pacemakers and implantable cardioverter defibrillators device interrogation was performed in order to estimate the duration of the episode. The $\mathrm{CHADS}_{2}$ [26] and $\mathrm{CHA}_{2} \mathrm{DS}_{2}$-VASc [27] scores, glomerular filtration rate (MDRD formula), body mass index and body surface area were calculated for all participants. Laboratory tests were performed within 24 hours of hospital admission for patients undergoing TEE in the emergency department and in the month preceding the transesophageal echocardiographic examination for participants undergoing elective TEE. Patients were thought to have congestive heart failure whenever concordant signs or symptoms were registered in their medical records. Vascular disease was defined by the presence of at least one of the following: previous myocardial infarction, peripheral artery disease or complex aortic plaque.

\section{Echocardiographic data acquisition}

All patients underwent a comprehensive imaging and Doppler echocardiographic examination using a commercially available system (Vivid 7 Dimension, GE Healthcare, Horten, Norway) according to our laboratory protocol. Examinations were performed by three trained transthoracic and transoesophageal echocardiographers, the images were stored on digital media for subsequent analysis using the commercially available software EchoPac Dimension PC version 108.1.4, GE Health Care, and were reviewed by two investigators.

M-mode and two-dimensional transthoracic images were acquired using a M4S probe (1.5-4.0 MHz), and were used to obtain the following LA measurements: LA AP diameter, LA area from 4-chamber view (4C), and LA volumes by the ellipsoid, single plane (1P) arealength and biplane (2P) area-length methods. These measurements were obtained at end-ventricular systole, 
from the frame immediately preceding mitral valve opening, as shown in Figure 1. LA AP diameter (D1) was measured by $\mathrm{M}$-mode from the parasternal longaxis view. LA area was measured using planimetry in TTE apical four-chamber and two chamber view. LA ellipsoid volume was calculated using AP (D1), mediallateral (D2) and superior-inferior (D3) LA diameters (Figure 1) and the formula: $4 / 3 \pi^{*}(\mathrm{D} 1 / 2) *(\mathrm{D} 2 / 2) *(\mathrm{D} 3 / 2)$. LA $1 \mathrm{P}$ area-length volume was obtained through the formula $8 / 3 \pi^{*} \mathrm{~A} 1^{2} / \mathrm{D} 3$, where $\mathrm{A} 1$ represents the area and D3 the superior-inferior LA diameter measured from apical $4 C$ view. LA $2 \mathrm{P}$ area-length volume was achieved with the formula $8 / 3 \pi^{*}[(\mathrm{~A} 1) *(\mathrm{~A} 2) / \mathrm{L}]$, where A2 represent the LA area 2 -chamber $(2 \mathrm{C})$ view, and $\mathrm{L}$ the shortest superiorinferior diameter measured in $4 C$ (D3) and 2C (D4) views (Figure 1). All these measurements were indexed to body surface area.

TEE images were acquired with a $6 \mathrm{~T}$ phased array multiplane transoesophageal probe $(2.9-7.0 \mathrm{MHz})$. The LA and LAA were imaged in different tomographic planes to detect the presence of LAA thrombus and SEC. LA thrombus was diagnosed by the presence of an echodense mass in the left atrium or the LAA [28]. Spontaneous echocardiographic contrast was diagnosed by the presence of characteristic dynamic smoke-like swirling echoes in the LA or the LAA, distinct from background white noise caused by excessive gain [29], and was classified according to the classification (1 to $4+$ ) proposed by Fatkin et al. [30]. Dense SEC was defined as grade 3+ or $4+$. Left atrial appendage flow velocities were assessed with a pulsed Doppler sample placed $1 \mathrm{~cm}$ from the entry of the LAA into the body of the LA. Maximum emptying and filling velocities were estimated from an average of five well-defined emptying and filling waves. Patients with maximum emptying and filling velocity $\leq 20 \mathrm{~cm} / \mathrm{s}$ were classified as having low flow velocities.

\section{Study endpoints}

The study endpoints were the TEE surrogate markers of stroke: LAA thrombus, LAA low flow velocities and dense SEC. The composite endpoint of LA abnormality (LA ABN) was defined by the presence of at least one of the previous markers.

\section{Statistical analysis}

Statistical analysis was performed using SPSS, version 17.0. Baseline characteristics were described with mean \pm standard deviation for continuous data and counts and proportions for categorical data. The Kolmogorov-Smirnov test was used to test the normal distribution of continuous variables. The Chi-square test, Student's $t$-test and nonparametric equivalent tests were used when appropriate. $\mathrm{P}$ values $<0.05$ (two-sided) were considered statistically significant.

A comparative univariate analysis of patients with and without LA ABN was performed to evaluate potential differences between the groups regarding demographic, clinical, echocardiographic and laboratorial parameters.

The discriminatory power of the indexed and nonindexed LA measurements (AP diameter, area $4 \mathrm{C}$, ellipsoid volume, $1 \mathrm{P}$ area-length volume and $2 \mathrm{P}$ area-length volume) to identify TEE surrogate markers of stroke (LAA thrombus, LAA low flow velocities, dense SEC and LA $A B N$ ) was evaluated through the receiver operating characteristic (ROC) curve, which refers to the ability of a model to assign a higher probability to patients reaching an endpoint than those who did not reach it. Comparisons of areas under ROC curves (AUC) were performed between LA indexed measurements, using MedCalc for Windows version 9.2.0.1. A ROC curve subanalysis was also carried out for patients previously under oral anticoagulation regarding LA thrombus, LAA low flow velocities or at least one of these two parameters.

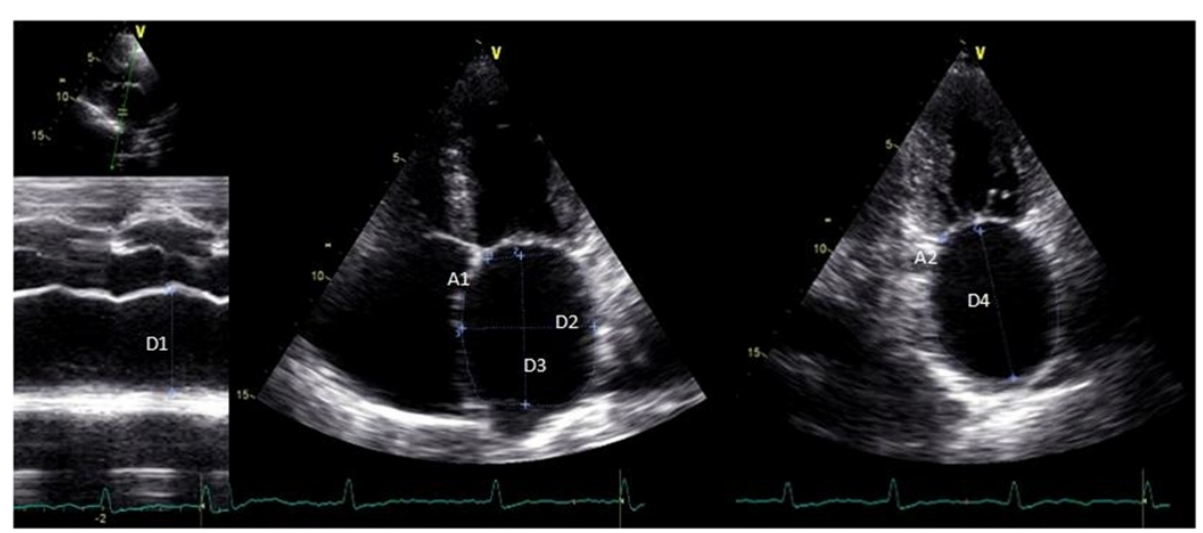

Figure 1 Echocardiographic parameters used to calculate the left atrial volumes. Legend: $A 1-L A$ area in $4 C$ view; $A 2-L A$ area in $2 C$ view; D1 - LA AP diameter; D2 - medial-lateral diameter; D3 - superior-inferior diameter in 4C view; D4 - superior-inferior diameter in 2C view. 
Finally, multivariate analysis (forward conditional method) was performed to identify independent predictors of TEE surrogate markers of stroke, among the different methods of LA size quantification and the parameters included in $\mathrm{CHADS}_{2}$ or $\mathrm{CHA}_{2} \mathrm{DS}_{2}$-VASc scores.

Inter- and intra-observer variability was assessed for the three echocardiographers using a sample composed of the first 50 patients included in the study: for dense SEC and LAA thrombus correlations were used; for LA measurements, we performed a Bland-Altman analysis using MedCalc for Windows version 9.2.0.1.

\section{Results}

\section{Study population}

Baseline characteristics of the 500 patients enrolled in this study are summarized in Table 1 . There was a lower prevalence of female gender (34.2\%). The average $\mathrm{CHADS}_{2}$ and $\mathrm{CHA}_{2} \mathrm{DS}_{2}$-VASc scores were $1.9 \pm 1.2$ and $3.2 \pm 1.7$, respectively. Forty point six per cent of patients were previously medicated with oral anticoagulants and 33.8\% with antiplatelet agents; in $33.8 \%$ of patients, one to three injections of enoxaparin were performed prior to TEE. The duration of the current atrial fibrillation episode was estimated to be longer than one year in $26.8 \%$ of patients
(Table 1). AF was persistent in $73.2 \%$ of patients $(\mathrm{n}=366)$ and long-standing persistent in $26.8 \%$ of patients $(n=134)$. TEE examinations identified 55 patients (11.1\%) with LAA thrombus, 66 (13.2\%) with low LAA flow velocities and 120 (24\%) with dense SEC. LA ABN was present in 29.6\% of patients $(\mathrm{n}=148)$.

The sub-analysis of demographic, clinical, echocardiographic and laboratorial characteristics of the study population according to the presence or absence of LA ABN is presented in Table 2. Patients with LA ABN had higher thromboembolic risk $\left(\mathrm{CHADS}_{2}: 2.1 \pm 1.1\right.$ vs. $1.8 \pm 1.2$, $\mathrm{p}=0.001 ; \mathrm{CHA}_{2} \mathrm{DS}_{2}$-VASc: $3.6 \pm 1.6$ vs. $\left.3.0 \pm 1.7, \mathrm{p}<0.001\right)$, were older $(70 \pm 8$ vs. $68 \pm 11, \mathrm{p}=0.02)$, had higher prevalence of congestive heart failure $(65.7 \%$ vs. $50.4 \%$, $\mathrm{p}=0.002)$ and vascular disease $(62.8 \%$ vs. $47.4 \%, \mathrm{p}=0.003)$, and less frequently a left ventricle ejection fraction $\geq 55 \%$ (58.8\% vs. $79.8 \%, \mathrm{p}<0.001)$. They presented higher values for all LA measurements performed and had longer AF duration (Table 2). Although patients with LA ABN were more often anticoagulated ( $50 \%$ vs. $36.6 \%, \mathrm{p}=0.01)$, there was no difference in the prevalence of effective anticoagulation $(20.9 \%$ vs. $20.7 \%, \mathrm{p}=\mathrm{ns})$ or in the average INR ( $1.5 \pm 0.7$ vs. $1.5 \pm 0.8, \mathrm{p}=\mathrm{ns})$ at the time TEE was performed.

Table 1 Study population baseline characteristics

\begin{tabular}{|c|c|c|c|}
\hline \multicolumn{4}{|c|}{ Baseline characteristics $(n=500)$} \\
\hline \multicolumn{2}{|c|}{ Demographics } & \multicolumn{2}{|c|}{ Medication previous to TEE } \\
\hline Age (years) & $69 \pm 10$ & Oral Anticoagulation & $40.6 \%(203)$ \\
\hline Age $\geq 75$ years & $31 \%(155)$ & Antiplatelet agents & $46.4 \%(232)$ \\
\hline Age $65-74$ years & $39.8 \%(199)$ & 1-3 doses of enoxaparine & $33.8 \%(169)$ \\
\hline Body Mass Index (Kg/m²) & $26.6 \pm 8.8$ & \multicolumn{2}{|c|}{ Echocardiographic characterization } \\
\hline Female gender & $34.2 \%(171)$ & LA AP diameter $(\mathrm{cm})$ & $4.7 \pm 0.7$ \\
\hline \multicolumn{2}{|c|}{ Clinical data } & LA area $\left(\mathrm{cm}^{2}\right)$ & $27.6 \pm 7.1$ \\
\hline Hypertension & $81.8 \%(409)$ & LA ellipsoid volume $\left(\mathrm{cm}^{3}\right)$ & $74.1 \pm 29.0$ \\
\hline Diabetes & $23.6 \%(118)$ & LA 1 P area-length volume $\left(\mathrm{cm}^{3}\right)$ & $113.8 \pm 47.7$ \\
\hline Previous Stroke/TIA & $14.8 \%(74)$ & LA 2 P area-length volume $\left(\mathrm{cm}^{3}\right)$ & $104.1 \pm 38.1$ \\
\hline Congestive heart failure & $54.8 \%(274)$ & LV ejection fraction $\geq 55 \%$ & $73.6 \%(368)$ \\
\hline Vascular disease $^{a}$ & $52 \%(260)$ & LAA thrombus & $11.1 \%(55)$ \\
\hline $\mathrm{CHADS}_{2}$ & $1.9 \pm 1.2$ & LAA low flow velocities & $13.2 \%(66)$ \\
\hline $\mathrm{CHA}_{2} \mathrm{DS}_{2}$-VASC & $3.2 \pm 1.7$ & Dense SEC & $24 \%(120)$ \\
\hline Pacemaker or ICD & $19.6 \%(98)$ & LA ABN & $29.6 \%(148)$ \\
\hline \multicolumn{2}{|c|}{ Estimated current AF episode duration } & \multicolumn{2}{|c|}{ Laboratorial evaluation } \\
\hline$\leq 48$ hours & $7 \%(35)$ & Haemoglobin (g/dL) & $13.2 \pm 1.8$ \\
\hline$<1$ week & $19.6 \%(98)$ & Platelets $\left(10^{3} / \mu \mathrm{L}\right)$ & $219.7 \pm 85.5$ \\
\hline$<1$ month & $36 \%(180)$ & INR & $1.5 \pm 0.8$ \\
\hline$>6$ months & $35.8 \%(179)$ & $I N R \geq 2.0$ & $20.8 \%(104)$ \\
\hline$>1$ year & $26.8 \%(134)$ & GFR $\left(\mathrm{mL} / \mathrm{min} / 1.73 \mathrm{~m}^{2}\right)$ & $62.4 \pm 33.0$ \\
\hline
\end{tabular}

Legend: GFR - glomerular filtration rate; ICD - implantable cardioverter defibrillator; INR - international normalized ratio; LV - left ventricle; TIA - transient ischaemic attack.

${ }^{a}$ Vascular disease is defined as having at least one of the following: myocardial infarctions, peripheral artery disease, and complex aortic plaque. 
Table 2 Sub-analysis of baseline characteristics according to the presence of left atrial abnormality

\begin{tabular}{|c|c|c|c|}
\hline Parameter & Without LA ABN & With LA ABN & $p$ \\
\hline \multicolumn{4}{|l|}{ Demographics } \\
\hline Age (years) & $68 \pm 11$ & $70 \pm 8$ & 0.02 \\
\hline Body Mass Index $\left(\mathrm{Kg} / \mathrm{m}^{2}\right)$ & $26.8 \pm 9$ & $26 \pm 8.1$ & 0.4 \\
\hline Female gender & $33 \%(116)$ & $37.2 \%(55)$ & 0.4 \\
\hline \multicolumn{4}{|l|}{ Clinical data } \\
\hline Hypertension & $80.8 \%(284)$ & $84.6 \%(125)$ & 0.4 \\
\hline Diabetes & $21.9 \%(77)$ & $28 \%(41)$ & 0.1 \\
\hline Previous Stroke/TIA & $13.2 \%(46)$ & $18.9 \%(28)$ & 0.1 \\
\hline Congestive heart failure & $50.4 \%(177)$ & $65.7 \%(97)$ & 0.002 \\
\hline Vascular disease $^{a}$ & $47.4 \%(167)$ & $62.8 \%(93)$ & 0.003 \\
\hline $\mathrm{CHADS}_{2}$ score & $1.8 \pm 1.2$ & $2.1 \pm 1.1$ & 0.001 \\
\hline $\mathrm{CHA}_{2} \mathrm{DS}_{2}$-VASc score & $3 \pm 1.7$ & $3.6 \pm 1.6$ & $<0.001$ \\
\hline Pacemaker or ICD & $18.8 \%(66)$ & $21.7 \%(32)$ & 0.7 \\
\hline \multicolumn{4}{|c|}{ Estimated current AF episode duration } \\
\hline$\leq 48$ hours & $8.5 \%(30)$ & $3.6 \%(5)$ & 0.06 \\
\hline$<1$ week & $24 \%(84)$ & $9.5 \%(14)$ & $<0.001$ \\
\hline$<1$ month & $40 \%(141)$ & $26.3 \%(39)$ & 0.001 \\
\hline$>6$ months & $31 \%(109)$ & $47.3 \%(70)$ & 0.001 \\
\hline$>1$ year & $22.2 \%(78)$ & $37.8 \%(51)$ & 0.001 \\
\hline \multicolumn{4}{|c|}{ Echocardiographic characterization } \\
\hline LA AP diameter, (cm) & $4.6 \pm 0.7$ & $4.8 \pm 0.8$ & 0.004 \\
\hline $\mathrm{LA}$ area $\left(\mathrm{cm}^{2}\right)$ & $26.4 \pm 6.8$ & $30.3 \pm 7.1$ & $<0.001$ \\
\hline LA ellipsoid volume $\left(\mathrm{cm}^{3}\right)$ & $70.5 \pm 28.2$ & $82.1 \pm 29.4$ & 0.001 \\
\hline $\begin{array}{l}\text { LA 1P area-length } \\
\text { volume }\left(\mathrm{cm}^{3}\right)\end{array}$ & $106.6 \pm 45.9$ & $130 \pm 47.7$ & $<0.001$ \\
\hline $\begin{array}{l}\text { LA } 2 \text { P area-length } \\
\text { volume }\left(\mathrm{cm}^{3}\right)\end{array}$ & $97.6 \pm 37.6$ & $117 \pm 35.9$ & $<0.001$ \\
\hline $\begin{array}{l}\text { Indexed LA AP diameter, } \\
\left(\mathrm{cm} / \mathrm{m}^{2}\right)\end{array}$ & $2.4 \pm 0.5$ & $2.7 \pm 0.4$ & $<0.001$ \\
\hline Indexed LA area $\left(\mathrm{cm}^{2} / \mathrm{m}^{2}\right)$ & $14.2 \pm 4.1$ & $16.9 \pm 4.1$ & $<0.001$ \\
\hline $\begin{array}{l}\text { Indexed LA ellipsoid } \\
\text { volume }\left(\mathrm{cm}^{3} / \mathrm{m}^{2}\right)\end{array}$ & $37.6 \pm 16.3$ & $45.3 \pm 16.3$ & $<0.001$ \\
\hline $\begin{array}{l}\text { Indexed LA IP area-length } \\
\text { volume }\left(\mathrm{cm}^{3} / \mathrm{m}^{2}\right)\end{array}$ & $56.9 \pm 24.7$ & $72.3 \pm 26.9$ & $<0.001$ \\
\hline $\begin{array}{l}\text { Indexed } L A 2 P \text { area-length } \\
\text { volume }\left(\mathrm{cm}^{3} / \mathrm{m}^{2}\right)\end{array}$ & $51.9 \pm 20.6$ & $64.8 \pm 20.9$ & $<0.001$ \\
\hline LV ejection fraction $\geq 55 \%$ & $79.8 \%(281)$ & $58.8 \%(87)$ & $<0.001$ \\
\hline \multicolumn{4}{|l|}{ Medication previous to TEE } \\
\hline Oral Antiocagulation & $36.6 \%(129)$ & $50 \%(74)$ & 0.01 \\
\hline Antiplatelet agents & $48.8 \%(172)$ & $40.5 \%(60)$ & 0.1 \\
\hline 1-3 doses of enoxaparine & $36.1 \%(127)$ & $28.3 \%(42)$ & 0.1 \\
\hline
\end{tabular}

Table 2 Sub-analysis of baseline characteristics according to the presence of left atrial abnormality (Continued)

\begin{tabular}{|c|c|c|c|}
\hline \multicolumn{4}{|l|}{ Laboratorial evaluation } \\
\hline Haemoglobin (g/dL) & $13.3 \pm 1.9$ & $13.1 \pm 1.6$ & 0.3 \\
\hline Platelets $\left(10^{3} / \mu \mathrm{L}\right)$ & $220.6 \pm 91.4$ & $217.5 \pm 69.4$ & 0.7 \\
\hline INR & $1.5 \pm 0.8$ & $1.5 \pm 0.7$ & 0.8 \\
\hline INR $\geq 2.0$ & $20.7 \%(73)$ & $20.9 \%(31)$ & 0.96 \\
\hline $\mathrm{GFR}\left(\mathrm{mL} / \mathrm{min} / 1.73 \mathrm{~m}^{2}\right)$ & $61.9 \pm 33.1$ & $63.8 \pm 32.8$ & 0.6 \\
\hline \multicolumn{4}{|c|}{$\begin{array}{l}\text { Legend: GFR - glomerular filtration rate; ICD - implantable cardioverter defibrillator } \\
\text { INR - international normalized ratio; LV - left ventricle; TIA - transient } \\
\text { ischaemic attack. } \\
\text { a Vascular disease is defined as having at least one of the following: myocardia } \\
\text { infarctions, peripheral artery disease, and complex aortic plaque. }\end{array}$} \\
\hline
\end{tabular}

\section{LA measurements for identifying surrogate markers of} stroke on TEE

Figure 2 presents the results of ROC curve analysis of the different indexed and non-indexed LA measurements for identifying LAA thrombus, LAA low flow velocities, dense SEC and LA ABN.

Except for LA AP diameter in identifying LA thrombus, all other LA measurements showed a good discriminatory ability in the prediction of the study endpoints (Figure 2). Indexing to body surface area increased the accuracy of every LA measurement to recognize each TEE surrogate marker of stroke (Figure 2).

Taking into account the possible influence of oral anticoagulation on dense SEC, a sub-analysis of the discriminatory ability of LA measurements for predicting the other surrogate markers of stroke (LA thrombus, LAA low flow velocities or at least one of these two parameters), was carried out for patients previously under oral anticoagulation (Figure 3). In this subset of 165 patients, LAA thrombus was found in 21 patients, LAA low flow velocities in 23 patients and at least one of these parameters in $40 \mathrm{pa}$ tients. There was a good discriminatory ability of the LA measurements for identifying LAA low flow velocities in this sample, though the results were not as consistent for identifying LAA thrombus (Figure 3).

\section{The most suitable TTE measurements to identify TEE surrogate markers of stroke}

The highest AUC for the prediction of study endpoints was achieved with indexed LA area $4 \mathrm{C}$ for LAA thrombus (AUC 0.788, $\mathrm{Cl}_{95 \%} 0.644-0.772, \mathrm{p}<0.001$ ), dense SEC (AUC 0.693, $\mathrm{CI}_{95 \%} 0.638-0.748, \mathrm{p}<0.001$ ) and LA ABN (AUC 0.705, $\mathrm{CI}_{95 \%} 0.654-0.755, \mathrm{p}<0.001$ ). Regarding LAA low flow velocities, the highest AUC was obtained with indexed $2 \mathrm{P}$ area-length method (AUC 0.737, $\mathrm{Cl}_{95 \%}$ $0.664-0.810, \mathrm{p}<0.001)$ - Figure 2 .

Generally, indexed LA area $4 \mathrm{C}$ and indexed $1 \mathrm{P}$ and $2 \mathrm{P}$ area-length methods showed a moderately high discriminatory power in the prediction of the study endpoints and stood out from all the other measurements. ROC 


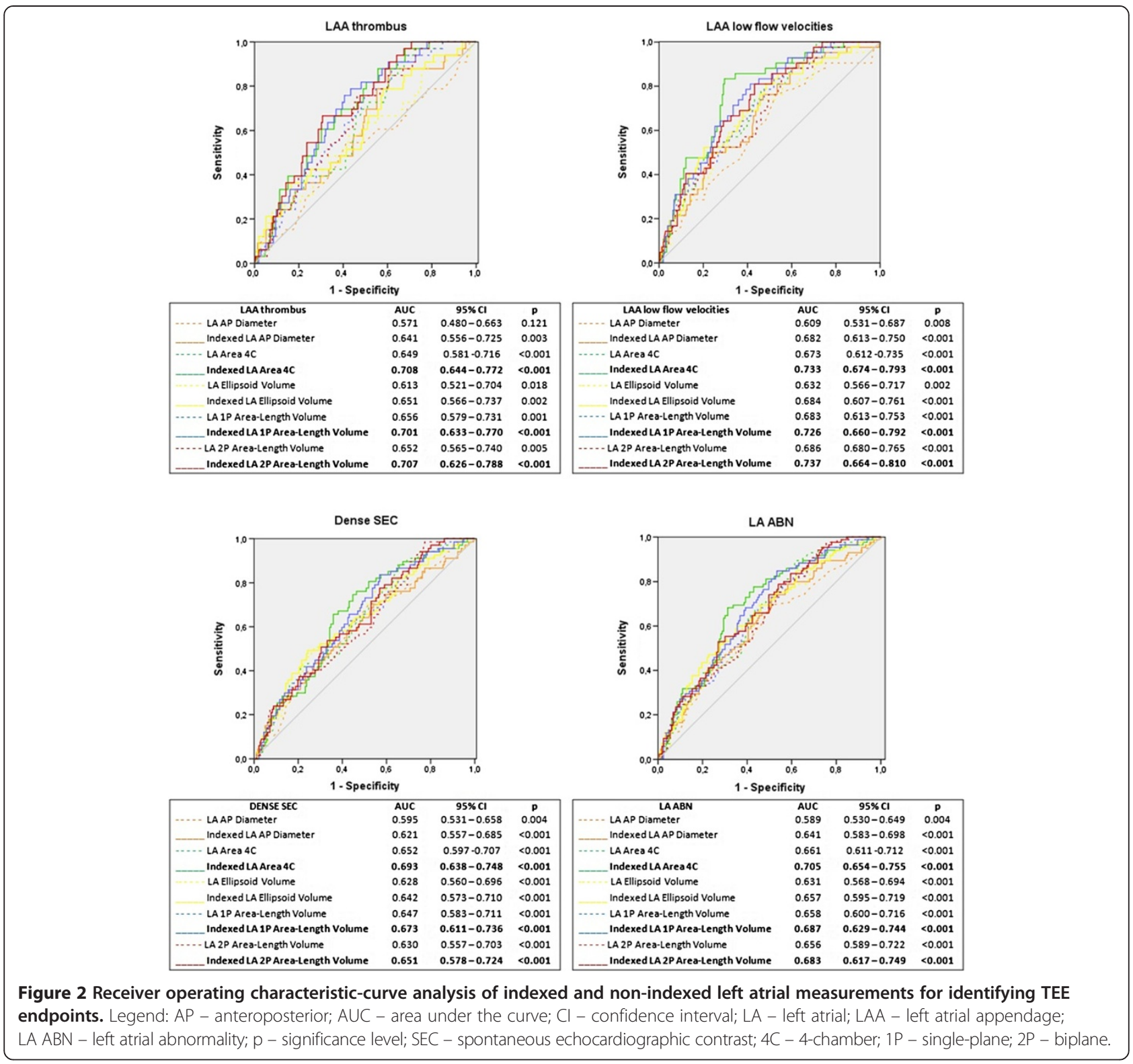

curve comparison for these three measurements did not reveal a significant difference between them (Table 3).

On multivariate analysis considering the different methods of LA size quantification and the parameters included in $\mathrm{CHADS}_{2}$ score, indexed LA area $4 \mathrm{C}$ was an independent predictor of LAA low flow velocities, dense SEC and LA ABN, while indexed $2 \mathrm{P}$ area-length volume was an independent predictor of LA thrombus (Table 4). The same analysis with the parameters of $\mathrm{CHA}_{2} \mathrm{DS}_{2^{-}}$ VASc score reached similar results, with exception for dense SEC (Table 4).

On multivariate analysis including the LA volumes and the $\mathrm{CHADS}_{2}$ score parameters, indexed 2P arealength volume was an independent predictor of LA thrombus, dense SEC and LA ABN; Indexed $1 \mathrm{P}$ area- length volume was independent predictor of LAA low flow velocities (Table 5). The same analysis considering $\mathrm{CHA}_{2} \mathrm{DS}_{2}$-VASc score parameters reached similar results, with exception for dense SEC (Table 5).

A multivariate analysis taking into account LA areas and $\mathrm{CHADS}_{2}$ or $\mathrm{CHA}_{2} \mathrm{DS}_{2}$-VASc score parameters revealed indexed LA area $4 \mathrm{C}$ as an independent predictor of all TEE endpoints (Table 6).

Inter- and intra-observer variability for the different LA size quantification methods, dense SEC and LAA thrombus is presented in Table 7.

\section{Discussion}

Our results suggest that LA dilation is associated with an increase in the prevalence of TEE markers of increased 

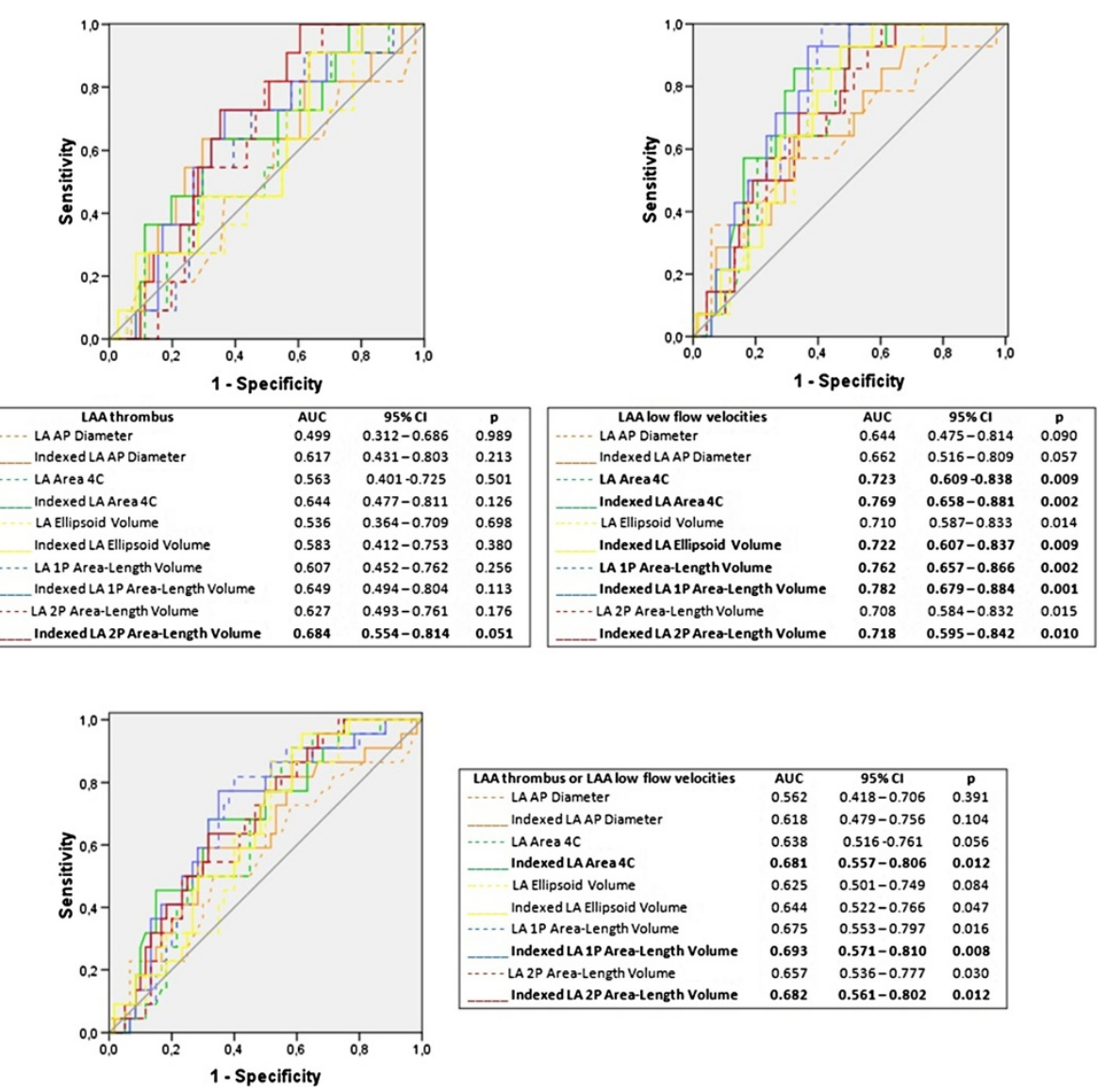

Figure 3 Receiver operating characteristic-curve sub-analysis of left atrial measurements for identifying LAA thrombus, LAA low flow velocities or at least one of one of these parameters, in patients under previous oral anticoagulation. Legend: AP - anteroposterior; AUC - area under the curve; $\mathrm{Cl}$ - confidence interval; LA - left atrial; LAA - left atrial appendage; $\mathrm{P}$ - significance level; 4C - 4-chamber; $1 \mathrm{P}$ - single-plane; 2P - biplane.

thromboembolic risk in patients with AF, independently from recognized clinical risk factors. A stronger association was found for measurements indexed to body surface area, with the best discriminative ability obtained with indexed LA area $4 \mathrm{C}$, indexed LA $1 \mathrm{P}$ area-length volume and indexed LA $2 \mathrm{P}$ area-length volume.

This is the first study to date evaluating and comparing the discriminative power of different methods for LA size measurement in the prediction of markers of left atrial stasis: LAA thrombus, dense SEC, LAA low flow velocities and $L A A B N$.

\section{Predictors of left atrial stasis}

The presence of thrombus in the LAA, dense SEC, LAA low flow velocities and LA ABN are strongly associated with thromboembolism and adverse outcomes in patients with AF [22-24]. Accordingly, TEE has been recommended to evaluate the risk of thromboembolism previous to procedures such as cardioversion or catheter ablation $[31,32]$.
In this study population, the presence of $\mathrm{LA} A B N$ was associated with longer AF duration and higher thromboembolic risk assessed by $\mathrm{CHADS}_{2}$ and $\mathrm{CHA}_{2} \mathrm{DS}_{2}$-VASc scores, due to a higher prevalence of recognized thromboembolic risk factors such as older age, heart failure, vascular disease and systolic dysfunction (Table 2). LA ABN was also associated with a larger left atrium, independently of the used method (Table 2). On multivariate analysis, indexed LA area $4 \mathrm{C}$ and indexed $2 \mathrm{P}$ area-length volume were predictors of LA ABN (Tables 4, 5 and 6). It is now established that LA enlargement is not considered part of the normal aging process, but related to underlying pathological processes such as systolic dysfunction, heart failure or vascular disease.

\section{Left atrial size - an underexplored marker of prothrombotic risk?}

For all evaluated methods, a larger LA was associated to LA ABN (Table 2). Also, most non-indexed and all indexed measurements showed moderate accuracy in the prediction of all thromboembolic risk markers 
Table 3 Cross Tabulation of ROC AUC between the different indexed methods

\begin{tabular}{|c|c|c|c|c|}
\hline $\begin{array}{l}\text { Indexed LA } \\
\text { AP diameter }\end{array}$ & $\begin{array}{l}\text { Indexed LA } \\
\text { Area 4C }\end{array}$ & $\begin{array}{c}\text { Indexed LA } \\
\text { elipsoid volume }\end{array}$ & $\begin{array}{l}\text { Indexed LA 1P } \\
\text { area-length volume }\end{array}$ & $\begin{array}{l}\text { Indexed LA 2P } \\
\text { area-length volume }\end{array}$ \\
\hline \multirow{17}{*}{$\begin{array}{l}\text { Indexed LA } \\
\text { AP diameter }\end{array}$} & LAAT $p=0.08$ & LAAT $p=0.910$ & LAAT $p=0.122$ & LAAT $p=0.082$ \\
\hline & DSEC $p=0.1$ & DSEC $p=0.231$ & DSEC $p=0.248$ & DSEC $p=0.389$ \\
\hline & LFV $p=0.024$ & LFV $p=0.358$ & LFV $p=0.127$ & LFV $p=0.245$ \\
\hline & LA ABN $p=0.046$ & LA ABN $p=0.187$ & LA ABN $p=0.154$ & LA ABN $p=0.249$ \\
\hline & & LAAT $p=0.037$ & LAAT $p=0.888$ & LAAT $p=0.795$ \\
\hline & Indexed LA Area 4C & DSEC $p=0.451$ & DSEC $p=0.466$ & DSEC $p=0.358$ \\
\hline & & LFV $p=0.064$ & LFV $p=0.061$ & LFV $p=0.069$ \\
\hline & & LA ABN $p=0.212$ & LA ABN $p=0.186$ & LA ABN $p=0.242$ \\
\hline & & \multirow{4}{*}{$\begin{array}{l}\text { Indexed LA } \\
\text { elipsoide volume }\end{array}$} & LAAT $p=0.010$ & LAAT $p=0.033$ \\
\hline & & & DSEC $p=0.722$ & DSEC $p=0.997$ \\
\hline & & & LFV $p=0.314$ & LFV $p=0.472$ \\
\hline & & & LA ABN $p=0.565$ & LA ABN $p=0.805$ \\
\hline & & & \multirow{5}{*}{$\begin{array}{l}\text { Indexed LA 1P } \\
\text { area-length volume }\end{array}$} & LAAT $p=0.766$ \\
\hline & & & & DSEC $p=0.608$ \\
\hline & & & & LFV $p=0.519$ \\
\hline & & & & LA ABN $p=0.633$ \\
\hline & & & & $\begin{array}{l}\text { Indexed LA 2P } \\
\text { area-length volume }\end{array}$ \\
\hline
\end{tabular}

Legend: AP - anteroposterior; DSEC - dense spontaneous echocardiographic contrast; LA - left atrial; LA ABN - left atrial abnormality; LAAT - left atrial appendage thrombus; LFV - left atrial appendage low flow velocities; $p$ - significance level; $4 C$ - 4-chamber; $1 P$ - single-plane; $2 P$ - biplane.

Table 4 Multivariate analysis including LA measurements and $\mathrm{CHADS}_{2} / \mathrm{CHA}_{2} \mathrm{DS}_{2}$-VASc parameters for prediction of TEE surrogate markers of stroke

\begin{tabular}{|c|c|c|c|c|}
\hline TEE markers of stroke & Independent predictors & OR & $\mathrm{Cl}_{95 \%}$ & $\mathbf{p}$ \\
\hline \multicolumn{5}{|c|}{ LA measurements $+\mathrm{CHADS}_{2}$ parameters } \\
\hline \multirow[t]{2}{*}{ LAA thrombus } & - Indexed LA 2P Area-Length Volume & 1.026 & $1.009-1.043$ & 0.003 \\
\hline & - Previous stroke/TIA & 4.080 & $1.647-10.102$ & 0.002 \\
\hline LAA LFV & - Indexed LA Area 4C & 1.174 & $1.083-1.272$ & $<0.001$ \\
\hline Dense SEC & - Indexed LA Area 4C & 1.090 & $1.018-1.167$ & 0.01 \\
\hline \multirow[t]{2}{*}{ LA ABN } & - Indexed LA Area 4C & 1.114 & $1.037-1.196$ & 0.003 \\
\hline & - Congestive heart failure & 2.022 & $1.109-3.690$ & 0.02 \\
\hline \multicolumn{5}{|c|}{ LA measurements $+\mathrm{CHA}_{2} \mathrm{DS}_{2}$-VASc parameters } \\
\hline \multirow[t]{2}{*}{ LAA thrombus } & - Indexed LA 2P Area-Length Volume & 1.028 & $1.010-1.046$ & 0.002 \\
\hline & - Previous stroke/TIA & 4.071 & $1.568-10.569$ & 0.004 \\
\hline LAA LFV & - Indexed LA Area 4C & 1.186 & $1.089-1.291$ & $<0.001$ \\
\hline \multirow[t]{2}{*}{ Dense SEC } & - Previous stroke/TIA & 2.675 & $1.158-6.180$ & 0.02 \\
\hline & - Congestive heart failure & 2.308 & $1.180-4.514$ & 0.02 \\
\hline \multirow[t]{2}{*}{ LA ABN } & - Indexed LA Area 4C & 1.106 & $1.029-1.190$ & 0.006 \\
\hline & - Congestive heart failure & 2.097 & $1.126-3.907$ & 0.02 \\
\hline
\end{tabular}

Legend: CI - confidence interval; LA - left atrial; LAA - left atrial appendage; LA ABN - left atrial abnormality; LFV - low flow velocities; OR - odds ratio; $\mathrm{p}$ - significance level; SEC - spontaneous echocardiographic contrast; TEE - transesophageal echocardiography; TIA - transient ischemic attack; vel - velocities; $4 C$ - 4-chamber; $2 \mathrm{P}$ - biplane. 
Table 5 Multivariate analysis including LA volume measurements and $\mathrm{CHADS}_{2} / \mathrm{CHA}_{2} \mathrm{DS}_{2}$-VASc parameters for prediction of TEE surrogate markers of stroke

\begin{tabular}{|c|c|c|c|c|}
\hline TEE markers of stroke & Independent predictors & OR & $\mathrm{Cl}_{95 \%}$ & $\mathbf{p}$ \\
\hline \multicolumn{5}{|c|}{ LA Volumes + $\mathrm{CHADS}_{2}$ parameters } \\
\hline \multirow[t]{2}{*}{ LAA thrombus } & - Indexed LA 2P Area-Length Volume & 1.026 & $1.009-1.043$ & 0.003 \\
\hline & - Previous stroke/TIA & 4.080 & $1.647-10.102$ & 0.002 \\
\hline LAA LFV & - Indexed LA 1P Area-Length Volume & 1.022 & $1.010-1.034$ & $<0.001$ \\
\hline \multirow[t]{3}{*}{ Dense SEC } & - Indexed LA 2P Area-Length Volume & 1.013 & $0.999-1.028$ & 0.07 \\
\hline & - Congestive heart failure & 1.968 & $1.024-3.783$ & 0.04 \\
\hline & - Previous stroke/TIA & 2.458 & $1.093-5.530$ & 0.03 \\
\hline \multirow[t]{2}{*}{ LA ABN } & - Indexed LA 2P Area-Length Volume & 1.021 & $1.006-1.035$ & 0.005 \\
\hline & - Congestive heart failure & 2.065 & $1.134-3.758$ & 0.02 \\
\hline \multicolumn{5}{|c|}{ LA Volumes $+\mathrm{CHA}_{2} \mathrm{DS}_{2}$-VASc parameters } \\
\hline \multirow[t]{2}{*}{ LAA thrombus } & - Indexed LA 2P Area-Length Volume & 1.028 & $1.010-1.046$ & 0.002 \\
\hline & - Previous stroke/TIA & 4.071 & $1.568-10.569$ & 0.004 \\
\hline LAA LFV & - Indexed LA 1P Area-Length Volume & 1.023 & $1.180-1.037$ & $<0.001$ \\
\hline \multirow[t]{2}{*}{ Dense SEC } & - Previous stroke/TIA & 2.675 & $1.158-6.180$ & 0.02 \\
\hline & - Congestive heart failure & 2.308 & $1.180-4.514$ & 0.02 \\
\hline \multirow[t]{2}{*}{ LA ABN } & - Indexed LA 2P Area-Length Volume & 1.019 & $1.005-1.034$ & 0.009 \\
\hline & - Congestive heart failure & 2.133 & $1.147-3.966$ & 0.02 \\
\hline
\end{tabular}

Legend: CI - confidence interval; LA - left atrial; LAA - left atrial appendage; LA ABN - left atrial abnormality; LFV - low flow velocities; OR - odds ratio; p - significance level; SEC - spontaneous echocardiographic contrast; TEE - transesophageal echocardiography; TIA - transient ischemic attack; vel - velocities; $1 \mathrm{P}$ - single-plane; $2 \mathrm{P}$ - biplane.

Table 6 Multivariate analysis including LA area measurements and $\mathrm{CHADS}_{2} / \mathrm{CHA}_{2} \mathrm{DS}_{2}$-VASc parameters for prediction of TEE surrogate markers of stroke

\begin{tabular}{|c|c|c|c|c|}
\hline TEE markers of stroke & Independent predictors & OR & $\mathrm{Cl}_{95 \%}$ & p \\
\hline \multicolumn{5}{|c|}{ LA Areas $+\mathrm{CHADS}_{2}$ parameters } \\
\hline \multirow[t]{2}{*}{ LAA thrombus } & - Indexed LA Area 4C & 1.119 & $1.047-1.196$ & 0.001 \\
\hline & - Previous stroke/TIA & 3.977 & $1.987-7.959$ & $<0.001$ \\
\hline LAA LFV & - Indexed LA Area 4C & 1.141 & $1.075-1.211$ & $<0.001$ \\
\hline Dense SEC & - Indexed LA Area 4C & 1.136 & $1.078-1.198$ & $<0.001$ \\
\hline \multirow[t]{2}{*}{ LA ABN } & - Indexed LA Area 4C & 1.142 & $1.083-1.204$ & $<0.001$ \\
\hline & - Congestive heart failure & 1.592 & $1.019-2.487$ & 0.04 \\
\hline \multicolumn{5}{|c|}{ LA Areas $+\mathrm{CHA}_{2} \mathrm{DS}_{2}$-VASc parameters } \\
\hline \multirow[t]{2}{*}{ LAA thrombus } & - Indexed LA Area 4C & 1.133 & $1.058-1.213$ & $<0.001$ \\
\hline & - Previous stroke/TIA & 3.932 & $1.917-8.069$ & $<0.001$ \\
\hline LAA LFV & - Indexed LA Area 4C & 1.139 & $1.071-1.212$ & $<0.001$ \\
\hline \multirow[t]{2}{*}{ Dense SEC } & - Indexed LA Area 4C & 1.125 & $1.065-1.189$ & $<0.001$ \\
\hline & - Previous Vascular disease & 1.930 & $1.180-3.154$ & 0.009 \\
\hline \multirow[t]{2}{*}{ LA ABN } & - Indexed LA Area 4C & 1.147 & $1.086-1.210$ & $<0.001$ \\
\hline & - Previous Vascular disease $e^{a}$ & 1.581 & $1.010-2.474$ & 0.05 \\
\hline
\end{tabular}

Legend: CI - confidence interval; LA - left atrial; LAA - left atrial appendage; LA ABN - left atrial abnormality; LFV - low flow velocities; OR - odds ratio; $\mathrm{p}$ - significance level; SEC - spontaneous echocardiographic contrast; TEE - transesophageal echocardiography; TIA - transient ischemic attack; vel - velocities; 4C - 4-chamber.

${ }^{a}$ Vascular disease is defined as having at least one of the following: myocardial infarctions, peripheral artery disease, and complex aortic plaque. 
Table 7 Inter- and intra-observer variability for the different LA quantification methods, dense spontaneous spontaneous echocardiographic contrast and left atrial appendage thrombus

\begin{tabular}{lccc}
\hline Inter-observer variability & A vs B & A vs C & B vs C \\
\hline LA AP Diameter (mean $\pm S D, \%)$ & $1.05 \pm 0.19$ & $1.04 \pm 0.2$ & $1.04 \pm 0.18$ \\
LA Area 4C (mean $\pm S D, \%)$ & $1.03 \pm 0.23$ & $1.04 \pm 0.24$ & $1.02 \pm 0.21$ \\
LA Ellipsoid Volume (mean $\pm S D, \%)$ & $1.12 \pm 0.36$ & $1.1 \pm 0.36$ & $1.08 \pm 0.33$ \\
LA 1P Area-Lenght Volume (mean $\pm S D, \%)$ & $1.09 \pm 0.44$ & $1.11 \pm 0.47$ & $1.06 \pm 0.41$ \\
LA 2P Area-Lenght Volume (mean $\pm S D, \%)$ & $1.05 \pm 0.28$ & $1.07 \pm 0.28$ & $1.03 \pm 0.27$ \\
Dense SEC & $R=0.797, p<0.001$ & $R=0.841, p<0.001$ \\
LAA Thrombus & $R=0.857, p<0.001$ & $R=0.001$ & $\mathbf{C}$ \\
\hline Intra-observer variability & $\mathbf{A}$ & $\mathrm{R}=1, \mathrm{p}<0.001$ & $1 \pm 0.07$ \\
\hline LA AP Diameter (mean $\pm S D, \%)$ & $1 \pm 0.08$ & $1 \pm 0.08$ & $1.01 \pm 0.1$ \\
LA Area 4C (mean $\pm S D, \%)$ & $1.01 \pm 0.11$ & $1.01 \pm 0.09$ & $0.98 \pm 0.11$ \\
LA Ellipsoid Volume (mean $\pm S D, \%)$ & $1.01 \pm 0.1$ & $01.01 \pm 0.1$ & $1.03 \pm 0.22$ \\
LA 1P Area-Lenght Volume (mean $\pm S D, \%)$ & $1.03 \pm 0.24$ & $1.02 \pm 0.2$ & $1.02 \pm 0.14$ \\
LA 2P Area-Lenght Volume (mean $\pm S D, \%)$ & $1.01 \pm 0.15$ & $R=1, p<0.001$ & $R=1, p<0.001$ \\
Dense SEC & $R=0.901, p<0.001$ & $R=1, p<0.001$ & $R=1, p<0.001$ \\
LAA Thrombus & $R=1, p<0.001$ & & \\
\hline
\end{tabular}

Legend: LA - left atrial; LAA - left atrial appendage; SEC - spontaneous echocardiographic contrast; 4C - 4-chamber; $1 \mathrm{P}$ - single-plane; $2 \mathrm{P}$ - biplane.

$A, B$ and $C$ represent the three different echocardiographers.

For LA measurements are presented the results of Bland-Altman analysis, expressed as mean \pm SD of the ratio of the measurements in comparison. For dense spontaneous spontaneous echocardiographic contrast and left atrial appendage thrombus are presented the variability is presented as a correlation.

assessed by TEE (Figure 2). Similar results were also found for identifying LAA low flow velocities or at least LAA low flow velocities or LAA thrombus in the subset of patients previously under oral anticoagulation. For predicting LAA thrombus in this subgroup, the results were not so consistent among the different LA measurements, however they may have been influenced by the small number of patients $(n=165)$ and the limited number of surrogate markers of stroke (LAA Thrombus: $\mathrm{n}=21$, low LAA flow velocities: $\mathrm{n}=23$, both $n=40$ ) included in this sample.

On multivariate analysis, LA size was predictor of LA $A B N$, LAA thrombus, LAA low flow velocities and dense SEC independently from most thromboembolic risk factors used in $\mathrm{CHADS}_{2}$ and $\mathrm{CHA}_{2} \mathrm{DS}_{2}$-VASc scores (Tables 4, 5 and 6). These results suggest that LA size may be used to predict stroke in patients with nonvalvular AF and, eventually, improve thromboembolic risk stratification of these patients. In one study of 334 patients with AF undergoing transesophageal echocardiography, indexed LA volume was a significant predictor of LAA thrombus (OR 1.02, $\mathrm{p}=0.02$ ) and added incremental predictive value to left ventricle ejection fraction [33]. Another study demonstrated that LA area 4C associated to left ventricular ejection fraction could be used to identify LAA thrombus, LAA low flow velocities, dense SEC or LA ABN, and further refine the ability of $\mathrm{CHADS}_{2}$ and $\mathrm{CHA}_{2} \mathrm{DS}_{2}$-VASc scores to identify these TEE surrogate markers of stroke [34]. However, the discriminative capability of an isolated LA measurement to identify TEE surrogate markers of stroke has never been evaluated.

Due to the wide variety of LA size quantification methods, it seems important to identify the most suitable and accurate method for thromboembolic risk assessment. When assessing LA size it is crucial to index results to body surface area, as confirmed by the observed improvement in AUC with the different indexed methods in our sample.

The indexed measurements of LA area 4C, LA 1P and $2 \mathrm{P}$ area-length volumes stood out among all LA measurements for their moderate to high discriminatory power in the prediction of LAA thrombus, LAA low flow velocities, dense SEC and LA ABN (Figure 2), without significant differences between them (Table 3). Indexed LA area $4 \mathrm{C}$ was an independent predictor of all TEE endpoints (Table 6). Importantly, for dense SEC, LAA low flow velocities and LA ABN, this predictive ability was independent of other LA measurements (Table 4). For LAA thrombus, indexed $2 \mathrm{P}$ area-length volume was a predictor of TEE surrogate markers of stroke, irrespectively of the other LA measurements (Table 4). When considered separately from LA area 4C, the indexed LA area-length volumes also showed a good predictive ability for TEE surrogate markers of stroke (Table 5).

LA enlargement is often asymmetrical, as enlargement in AP axis may be limited by the thoracic cavity, and it 
may also occur in medial-lateral or superior-inferior axes $[11,14]$. Thus, LA AP diameter has been considered inaccurate, while LA areas or volumes assessed by TTE rely on fewer geometric assumptions. The $2 \mathrm{P}$ volume, using either the area-length or the discs formula, is the method currently recommended for LA size quantification [19]. In our study, this indexed method has also proved to be one of the most suitable to indicate the presence of TEE surrogate markers of stroke, yet singleplane area-length and area $4 \mathrm{C}$ methods showed a similar ability for this purpose.

Russo $C$ and colleagues [13] evaluated single-plane and biplane methods for the assessment of LA volume against three-dimensional echocardiography in 527 participants of a community-based Cohort. They found strong correlations between single- and biplane LA volume measurements $(\mathrm{r}=0.95, \mathrm{p}<0.01)$, and single$(\mathrm{r}=0.93, \mathrm{p}<0.01)$ and biplane $(\mathrm{r}=0.93, \mathrm{p}<0.01)$ arealength with three-dimensional volumes, although single-plane method had a suboptimal agreement for categorical classification. They suggested that singleplane method could simplify and expedite LA volume evaluation, but specific cut-off points should be developed for this method.

Similar results were also found for LA area $4 \mathrm{C}$ and single-plane area-length methods in the study of Badano LP and colleagues [15], who found an excellent correlation between LA area $4 \mathrm{C}(\mathrm{r}=0.94, \mathrm{p}<0.0001)$, single-plane volume $(\mathrm{r}=0.98, \mathrm{p}<0.0001)$ and biplane volume $(\mathrm{r}=0.99, \mathrm{p}<0.0001)$ with volumes determined by three-dimensional echocardiography. They verified that the various methods of LA size quantification were not comparable, with a better agreement for singleand biplane volume methods, while LA area misled LA dilatation severity. They concluded that LA area inaccuracy was due mainly to inappropriate cut-off values than to the parameter itself. Furthermore, they suggested that the small additional accuracy obtained by using the biplane instead of the single-plane arealength method could allow the use of the single-plane method for routine clinical use [15]. Interestingly, reference ranges are also not available for indexed LA area $4 \mathrm{C}$ method in the last joint recommendations for chamber quantification [19].

In our study we found no significant differences when comparing indexed LA area $4 \mathrm{C}$, LA $2 \mathrm{P}$ and $1 \mathrm{P}$ arealength volume for the discrimination of TEE markers of thromboembolic risk. This may be due to fact that differences between methods may be small and our sample may lack the necessary statistical power to demonstrate them. Further studies, sufficiently powered to assess this issue may be needed. However, at present moment there is no evidence suggesting that one should be preferred over the others for this specific aim.

\section{Limitations}

There are several limitations in this study that must be highlighted. First, this was a single-centre study, whose sample was not powered for enabling comparisons between some of the different methods used for assessing LA size.

Second, at the time of TEE, $40.6 \%$ of the study population was under oral anticoagulation, which may have had an impact in the prevalence of LA stasis markers. However, we believe this study cohort is representative of the general population of patients with AF and, as such, we decided not to exclude patients under oral anticoagulation. Moreover, some of these patients were not under therapeutic INR values and it is known that thrombi may arise even under therapeutic INR.

\section{Conclusion}

LA enlargement, determined by indexed LA AP diameter, and indexed and non-indexed LA area $4 \mathrm{C}$ and volumes, is suitable to identify LAA thrombus, LAA low flow velocities, dense SEC and LA ABN in patients with non-valvular AF. The indexed measurements of LA area $4 \mathrm{C}$, single- and biplane area-length volumes are the most accurate methods for this purpose, and may be used to stratify thromboembolic risk in these patients.

\section{Abbreviations}

AF: Atrial fibrillation; AP: Anteroposterior, for diameter measured by M-mode; AUC: Area under receiver operating characteristic curve; LA: Left atrial; LAA: Left atrial appendage; LA ABN: Left atrial abnormality; ROC curve: Receiver operating characteristic curve; SEC: Spontaneous echocardiographic contrast; TEE: Two-dimensional transesophageal echocardiography; TTE: Two-dimensional transthoracic echocardiography; 2C: Two-chamber view; 4C: Four-chamber view; 1P: Single-plane; 2P: Biplane.

\section{Competing interests}

The authors declare that they have no competing interests.

\section{Authors' contributions}

AF: conception and design, acquisition, analysis and interpretation of data, draft of the manuscript; RP: design, acquisition, analysis and interpretation of data, critical review of the manuscript; SB: critical review of the manuscript; LP: acquisition, analysis and interpretation of data; JT: acquisition of echocardiography images; $A B$ : acquisition of echocardiography images; MC: gave final approval of the version to be published; LG: gave final approval of the version to be published. All authors have read and approved the final version of the manuscript and provided insight for its elaboration.

\section{Author details}

${ }^{1}$ Cardiology Department, Coimbra's Hospital and University Centre - General Hospital, Coimbra, Portugal. 'Faculty of Medicine, University of Coimbra, Coimbra, Portugal.

Received: 2 February 2014 Accepted: 12 June 2014

Published: 22 July 2014

\section{References}

1. Benjamin EJ, D'Agostino RB, Belanger AJ, Wolf PA, Levy D: Left atrial size and the risk of stroke and death. The Framingham Heart Study. Circulation 1995, 92:835-841.

2. Tsang T, Barnes M, Bailey K, Leibson CL, Montgomery SC, Takemoto Y, Diamond PM, Marra MA, Gersh BJ, Wiebers DO, Petty GW, Seward JB: Left 
atrial volume: important risk marker of incident atrial fibrillation in 1655 older men and women. Mayo Clin Proc 2001, 76:467-475.

3. Barnes ME, Miyasaka Y, Seward JB, Gersh BJ, Rosales AG, Bailey KR, Petty GW, Wiebers DO, Tsang TS: Left atrial volume in the prediction of first ischemic stroke in an elderly cohort without atrial fibrillation. Mayo Clin Proc 2004, 79:1008-1014

4. Tsang TS, Gersh BJ, Appleton CP, Tajik AJ, Barnes ME, Bailey KR, Oh JK, Leibson C, Montgomery SC, Seward JB: Left ventricular diastolic dysfunction as a predictor of the first diagnosed nonvalvular atrial fibrillation in 840 elderly men and women. J Am Coll Cardiol 2002, 40:1636-1644.

5. Tsang TS, Barnes ME, Gersh BJ, Bailey KR, Seward JB: Risks for atrial fibrillation and congestive heart failure in patients $\geq 65$ years of age with abnormal left ventricular diastolic relaxation. Am J Cardiol 2004, 93:54-58.

6. Aronow WS, Gutstein H, Hsieh FY: Risk factors for thromboembolic stroke in elderly patients with chronic atrial fibrillation. Am J Cardiol 1989, 63:366-367

7. Aronow WS, Ahn C, Kronzon I, Gutstein H: Risk factors for new thromboembolic stroke in patients $>$ or $=62$ years of age with chronic atrial fibrillation. Am J Cardiol 1998, 82:119-121.

8. Osranek M, Bursi F, Bailey KR, Grossardt BR, Brown RD, Kopecky SL, Tsang TS, Seward JB: Left atrial volume predicts cardiovascular events in patients originally diagnosed with lone atrial fibrillation: three-decade follow-up. Eur Heart J 2005, 26:2556-2561.

9. Caplan LR, D'Cruz I, Hier DB, Reddy H, Shah S: Atrial size, atrial fibrillation and stroke. Ann Neurol 1986, 19:158-161.

10. Vaziri SM, Larson MG, Benjamin EJ, Levy D: Echocardiographic predictors of nonrheumatic atrial fibrillation. The Framingham Heart Study. Circulation 1994, 89:724-730.

11. Leung DY, Boyd A, Arnold H, Chi C, Thomas L: Echocardiographic evaluation of left atrial size and function: current understanding, pathophysiologic correlates, and prognostic implications. Am Heart J 2008, 156:1056-1064.

12. Tsang TS, Abhayaratna WP, Barnes ME, Miyasaka Y, Gersh BJ, Bailey KR, Cha SS, Seward JB: Prediction of cardiovascular outcomes with left atrial size. Is volume superior to area or diameter? J Am Coll Cardiol 2006, 47:1018-1023.

13. Russo C, Hahn RT, Jin Z, Homma S, Sacco RL, Di Tullio MR: Comparison of echocardiographic single- vs biplane method in the assessment of left atrial volume and validation by real time three-dimensional echocardiography. J Am Soc Echocardiogr 2010, 23(9):954-960

14. Abhayaratna WP, Seward JB, Appleton CP, Douglas PS, Oh JK, Tajik AJ, Tsang TSM: Left atrial size: physiologic determinants and clinical applications. J Am Coll Cardiol 2006, 47:2357-2363.

15. Badano LP, Pezzutto N, Marinigh R, Cinello M, Nucifora G, Pavoni D, Gianfagna P, Fioretti PM: How many patients would be misclassified using M-mode and two-dimensional estimates of left atrial size instead of left atrial volume? A three-dimensional echocardiographic study. J Cardiovasc Med, 9:476-484.

16. Maddukuri PV, Vieira ML, DeCastro S, Maron MS, Kuvin JT, Patel AR, Pandian NG: What is the best approach for the assessment of left atrial size? Comparison of various unidimensional and Two-dimensional parameters with three-dimensional echocardiographically determined left atrial volume. J Am Soc Echocardiogr 2006, 19:1026-1032.

17. Khankirawatana B, Khankirawatana S, Porter T: How should left atrial size be reported? Comparative assessment with use of multiple echocardiographic methods. Am Heart J 2004, 147:369-374.

18. Wang Y, Gutman JM, Heilbron D, Wahr D, Schiller NB: Atrial volume in a normal adult population by two-dimensional echocardiography. Chest 1984, 86:595-601.

19. Lang RM, Bierig M, Devereux RB, Flachskampf FA, Foster E, Pellikka PA, Picard MH, Roman MJ, Seward J, Shanewise J, Solomon S, Spencer KT, Sutton MSJ, Stewart W: Recommendations for chamber quantification. Eur J Echocardiogr 2006, 7:79-108.

20. Zabalgoitia M, Halperin JL, Pearce LA, Blackshear JL, Asinger RW, Hart RG Stroke Prevention in Atrial Fibrillation III Investigators. Transesophageal echocardiographic correlates of clinical risk of thromboembolism in nonvalvular atrial fibrillation. J Am Coll Cardiol 1998, 31:1622-1626.

21. Leung DY, Black IW, Cranney GB, Hopkins AP, Walsh WF: Prognostic implications of left atrial spontaneous echo contrast in nonvalvular atrial fibrillation. J Am Coll Cardiol 1994, 24:755-762.
22. Albers GW, Dalen JE, Laupacis A, Manning WJ, Petersen P, Singer DE: Antithrombotic therapy in atrial fibrillation. The Sixth ACCP Conference on Antithrombotic and Thrombolytic Therapy. Chest 2001, 119:194S-206S.

23. Lip GYH, Lane D, van Walraven C, Hart RG: Additive role of plasma von Willebrand Factor levels to clinical factors for risk stratification in patients with atrial fibrillation. Stroke 2006, 37:2294-2300.

24. The Stroke Prevention in Atrial Fibrillation Investigators Committee on Echocardiography: Transesophageal echocardiographic correlates of thromboembolism in high-risk patients with nonvalvular atrial fibrillation. Ann Intern Med 1998, 128:639-647.

25. Providência $R$, Trigo J, Paiva $L$, Barra $S$ : The role of echocardiography in thromboembolic risk assessment of patients with nonvalvular atrial fibrillation. J Am Soc Echocardiogr 2013, 26:801-812.

26. Gage BF, Waterman AD, Shannon W, Boechler M, Rich MW, Radford MJ: Validation of clinical classification schemes for predicting stroke: results from the National Registry of atrial fibrillation. JAMA 2001, 285:2864-2870.

27. Lip GY, Nieuwlaat R, Pisters R, Lane DA, Crijns HJ: Refining clinical risk stratification for predicting stroke and thromboembolism in atrial fibrillation using a novel risk factor-based approach: the euro heart survey on atrial fibrillation. Chest 2010, 137:263-272.

28. Beppu S, Park YD, Sakakibara H, Nagata S, Nimura Y: Clinical features of intracardiac thrombosis based on echocardiographic observation. Jpn Cite J 1984, 48:75-82.

29. Beppu S, Nimura Y, Sakakihara H, Nagata S, Park YD, Izumi S: Smoke-like echo in the left atrial cavity in mitral valve disease: its features and significance. J Am Coll Cardiol 1985, 6:744-749.

30. Fatkin D, Kelly RP, Feneley MP: Relations between left atrial appendage blood flow velocity, spontaneous echocardiographic contrast and thromboembolic risk in vivo. J Am Coll Cardiol 1994, 23:961-969.

31. Camm AJ, Kirchhof P, Lip GY, Schotten U, Savelieva I, Ernst S, Gelder ICV, Al-Attar N, Hindricks G, Prendergast B, Heidbuchel H, Alfieri O, Angelini A Atar D, Colonna P, De Caterina R, De Sutter J, Goette A, Gorenek B, Heldal M, Hohloser SH, Kolh P, Le Heuzey JY, Ponikowski P, Rutten FH: Guidelines for the management of atrial fibrillation: the task force for the management of atrial fibrillation of the European Society of Cardiology (ESC). Eur Heart J 2010, 31:2369-2429.

32. Wann LS, Curtis AB, Ellenbogen KA, Estes M, Ezekowitz MD, Jackman WM, January CT, Lowe JE, Page RL, Slotwiner DJ, Stevenson WG, Tracy CM: $2011 \mathrm{ACCF} / \mathrm{AHA} / \mathrm{HRS}$ focused update on the management of patients with atrial fibrillation (update on dabigatran): a report of the American College of Cardiology Foundation/American Heart Association Task

Force on Practice Guidelines. Circulation 2011, 123:1144-1150.

33. Ayirala S, Kumar S, O'Sullivan DM, Silverman DI: Echocardiographic predictors of left atrial appendage thrombus formation. J Am SoC Echocardiogr 2011, 24:499-505.

34. Providência R, Botelho A, Trigo J, Quintal N, Nascimento J, Mota P, Leitão-Marques A: Possible refinement of clinical thromboembolism assessment in patients with atrial fibrillation using echocardiographic parameters. Europace 2012, 14:36-45.

\section{doi:10.1186/1476-7120-12-28}

Cite this article as: Faustino et al:: Which method of left atrium size quantification is the most accurate to recognize thromboembolic risk in patients with non-valvular atrial fibrillation? Cardiovascular Ultrasound 2014 12:28.

\section{Submit your next manuscript to BioMed Central and take full advantage of:}

- Convenient online submission

- Thorough peer review

- No space constraints or color figure charges

- Immediate publication on acceptance

- Inclusion in PubMed, CAS, Scopus and Google Scholar

- Research which is freely available for redistribution 